\title{
Microsatellite Loci Transferability in Chestnut
}

\author{
Ying Wang \\ Wuhan Botanical Garden, Chinese Academy of Sciences, Wuhan, Hubei 430074, \\ China, and Graduate School of the Chinese Academy of Sciences, Beijing 100039, China \\ Ming Kang and Hongwen Huang ${ }^{1}$ \\ South China Botanical Garden, Chinese Academy of Sciences, Guangzhou, \\ Guangdong 510650, China
}

\begin{abstract}
Additional INDEX words. SSR, Castanea, genetic diversity
Abstract. Cross-species amplification of 55 microsatellite loci developed in european chestnut (Castanea sativa Mill.) and japanese chestnut (C. crenata Sieb \& Zucc.) was tested in three chestnut species from China $[C$. mollissima Blume, C. seguinii Dode, and $C$. henryi (Skan.) Rehder \& Wilson]. Among all the tested loci, 47 (85.5\%), 47 (85.5\%), and 44 $(\mathbf{8 0} \%)$ were successfully amplified in each of the three Chinese species, respectively. All microsatellite loci tested from $C$. crenata successfully amplified in the Chinese species, while only $80.5 \%, 80.5 \%$, and $73.2 \%$ of the loci originating from $C$. sativa amplified in the three Chinese species. The level of polymorphism and mean number of alleles was $58.2 \%$ and 4.12 for $C$. mollissima, $60 \%$ and 4.64 for $C$. seguinii, and $60 \%$ and 4.76 for $C$. henryi, with mean observed heterozygosity ranging from 0.440 to 0.549 and mean expected heterozygosity ranging from 0.506 to 0.615 . Transferability of Castanea Mill. microsatellites provides a powerful tool for chestnut breeding programs and conservation genetic studies of Castanea species.
\end{abstract}

The genus Castanea is comprised of seven economically and ecologically important timber tree taxa that are widely distributed in the temperate forests of the Northern Hemisphere (Johnson, 1988). The center of origin of Castanea is located in China where three endemic chestnuts occur: C. mollissima, C. seguinii, and C. henryi (Lang, 2004; Lang and Huang, 1999). C. mollissima, C. crenata, and C. sativa are economically important for chestnut nut production. C. mollissima is valued for its resistance to chestnut blight fungus [Cryphonectria parasitica (Murrill) Barr] and has been used as a source of blight resistance genes in chestnut breeding (Rutter et al., 1990). A closely related species, C. seguinii, has little value for nut production due to its small nut size, but it is highly valuable for chestnut breeding because of its dwarf stature, precocity, and heavy yielding of nuts that provide a food source for wildlife (Jaynes, 1979). Castanea henryi is a keystone forest plant and a good timber tree. Many Chinese chestnut cultivars and landraces have been cultivated for centuries in China. However, development of a modern chestnut industry is hampered in China because of cultivar mixing and lack of international standards for chestnut marketing. Therefore, there is an urgent need for cultivar identification and fingerprinting of traditional cultivars and landraces using molecular markers. Moreover, due to overharvesting and deforestation, natural resources and wild populations of Chinese native chestnut species have been seriously damaged in recent decades. Thus, for the formulation of a long-term conservation strategy, the inventory of natural genetic diversity of Chinese Castanea populations is critical, and a set of molecular markers is also required.

Received for publication 29 May 2008. Accepted for publication 8 July 2008 This research was partially supported by the National Natural Science Foundation of China (No. 30770219) and by the KIP Pilot Project of Chinese Academy of Science (KSCX2-YW-N-061).

We thank Zhang Zhonghui for sampling assistance in the field work. We likewise acknowledge BCSU No. 080112 of Laboratory of Biodiversity Conservation and Sustainable Utilization, SCBG-CAS.

${ }^{1}$ Corresponding author. E-mail: huanghw@mail.scbg.ac.cn.
Microsatellites or simple sequence repeats (SSRs) are DNA segments containing short sequence repeats (1-6 nucleotides) and have been widely recognized as powerful and informative markers due to their abundance, codominance, high polymorphism, and ease of use with the polymerase chain reaction (PCR) (Kuleung et al., 2004; Peakall et al., 1998). In plants, SSRs are useful for cultivar identification, genetic linkage mapping, and marker-assisted selection in breeding and population genetic studies (Barreneche et al., 1998; Butcher et al., 2000; Steinkellner et al., 1997). Microsatellites have been developed in Castanea species, for example, in C. crenata and C. sativa (Buck et al., 2003; Marinoni et al., 2003; Yamamoto et al., 2003), and also have recently been applied in the genetic studies of C. crenata and american chestnut [C. dentata (Marsh.) Borkh] (Kubisiak and Roberds, 2006; Tanaka et al., 2005). However, few studies have been reported on Chinese Castanea species using microsatellite markers due to the lack of efforts in development of microsatellite markers for Chinese chestnuts. Nevertheless, the lack of microsatellite markers directly developed from Chinese chestnuts could be largely solved by considering the great conservation of SSR flanking regions in closely related species (Bushar et al., 2001; Schnell et al., 2005; Steinkellner et al., 1997). Thus, screening primers from different sources can offer a potential chance for the development of SSR markers for species without prior sequence information (reviewed by Barbará et al., 2007). In the present study, we analyzed the transferability of 55 microsatellite loci originally developed from C. sativa and C. crenata in three Chinese endemic Castanea species (C. mollissima, C. seguinii, and C. henryi), and tested this set of SSR loci for robust use in a genetic study of Chinese Castanea species.

\section{Materials and Methods}

Plant materials and DNA extraction. To test the transferability of microsatellite loci, 30 individuals of each the three Chinese species were randomly sampled as a test population 
from Jishou city of Hunan province (C. mollissima), Pingba county of Guizhou province (C. seguinii) and Zigui county of Hubei province $(C$. henryi). Young leaves were collected and stored with silica gel until DNA extraction. About $0.25 \mathrm{~g}$ of dry leaf tissues were ground into powder in Eppendorf tube containing $5 \times 5$-mm magnetic bead, using a FastPrep FP 2000 mill (Thermo Electron, Waltham, MA). DNA was extracted following a modified protocol from Doyle and Doyle (1987) with some modifications: the extraction buffer contained $10 \%$ polyvinylpyrrolidone and $2 \% \mathrm{Na}_{2} \mathrm{~S}_{2} \mathrm{O}_{5}$, and the lysis buffer contained $3 \%$ cetyltrimethyl ammonium bromide and $2 \% \mathrm{Na}_{2} \mathrm{~S}_{2} \mathrm{O}_{5}$. DNA was dissolved in $200 \mu \mathrm{L}$ of TE solution (10 mm Tris-HCl buffer solution, $\mathrm{pH} 8.3$, and $1 \mathrm{~mm}$ EDTA, $\mathrm{pH}$ 8.0); $20 \mu \mathrm{g}$ of RNase was added to the solution, which was then incubated at $37^{\circ} \mathrm{C}$ for $1 \mathrm{~h}$. DNA concentration was quantified by spectrophotometry (GENEQUANT; Eppendorf, Hamburg, Germany).

PCR AMPlifiCATION AND Data ANALYSIs. Fifty-five pairs of SSR primers were tested (Table 1), 14 pairs from C. crenata (Yamamoto et al., 2003) and 41 from $C$. sativa (eight were reported by Buck et al., 2003 and 33 by Marinoni et al., 2003). For transferability analyses, each locus was first amplified using four individuals of each species, randomly chosen from the 30 individuals sampled. PCR reactions were performed in a final volume of $10 \mu \mathrm{L}$ containing $10 \mathrm{~mm}$ Tris- $\mathrm{HCl}(\mathrm{pH} 8.3), 50 \mathrm{~mm}$ $\mathrm{KCl}, 1.5 \mathrm{~mm} \mathrm{MgCl}_{2}, 0.5 \mu \mathrm{m}$ each primer, $0.2 \mathrm{~mm}$ dNTPs, $25 \mathrm{ng}$ of genomic DNA, and $0.25 \mathrm{U}$ of Taq polymerase (Shenergy Biocolors, Shanghai, China). The PCR amplification was conducted in a Mastercycler gradient thermocycler (Eppendorf) using the following thermal profile: $5 \mathrm{~min}$ of denaturation at $95{ }^{\circ} \mathrm{C}, 35$ cycles of $1 \mathrm{~min}$ at $94{ }^{\circ} \mathrm{C}, 45 \mathrm{~s}$ at the annealing temperature of $45{ }^{\circ} \mathrm{C}$ to $67{ }^{\circ} \mathrm{C}$ depending on the different primers and different species (Buck et al., 2003; Marinoni et al., 2003; Yamamoto et al., 2003), $1 \mathrm{~min}$ and $30 \mathrm{~s}$ at $72{ }^{\circ} \mathrm{C}$, with a final extension at $72{ }^{\circ} \mathrm{C}$ for $7 \mathrm{~min}$. The amplification products combined with three-quarters volume of formamide loading buffer (98\% formamide, $10 \mathrm{~mm}$ EDTA, $\mathrm{pH} 8.0,0.25 \%$ bromphenol blue, and $0.25 \%$ xylene cyanol) were denatured at $94{ }^{\circ} \mathrm{C}$ for $5 \mathrm{~min}$ and were electrophoresed in $6 \%$ denaturing polyacrylamide gels using Sequi-Gen GT System (BioRad, Hercules, CA). Electrophoresis was carried out with $1 \times$ Tris-borate-EDTA buffer for $1.5 \mathrm{~h}$ at $55 \mathrm{~W}$. Silver staining was conducted according to the protocol of Sanguinetti et al. (1994).

For each microsatellite locus, sizes of the alleles were estimated by comparison with standard size DNA markers (25-bp DNA ladder; Promega, Madison, WI) and were scored across all of the samples manually. Control samples were used to ensure that the same alleles were obtained whatever the method used. For those primers that produced clear bands and reproducible amplification, 30 individuals of each species were genotyped. GENEPOP software (version 3.4; Raymond and Rousset, 1995) was used to perform exact tests for the deviations from Hardy-Weinberg equilibrium (HWE) and linkage disequilibrium (LD) within populations using the Markov chain method (Guo and Thompson, 1992). The number of alleles per locus $\left(N_{\mathrm{a}}\right)$, observed heterozygosity $\left(H_{\mathrm{O}}\right)$, and expected heterozygosity $\left(H_{\mathrm{E}}\right)(\mathrm{Nei}, 1978)$ were estimated using software GenAlEx, version 6.0 (Peakall and Smouse, 2006). Total exclusion power of the first $\left[\operatorname{Pr}\left(E \mathrm{x}_{1}\right)\right]$ and second parent $\left[\operatorname{Pr}\left(E \mathrm{x}_{2}\right)\right]$ were estimated using CERVUS, version 2.0 (Marshall et al., 1998).

\section{Results and Discussion}

Of the 55 microsatellite loci assayed, 90.9\% (including 14 loci from C. crenata and 36 from C. sativa) were amplified in at least one of the species tested, and 74.5\% (14 from C. crenata and 27 from C. sativa) could be amplified in all three Chinese species (Table 1). Figure 1 shows transferability of two microsatellite loci, one locus from C. sativa (Fig. 1A), the other from C. crenata (Fig. 1B), successfully amplified in the Chinese species. A total of $85.5 \%$ loci (14 loci from C. crenata and 33 from C. sativa) can be cross-species amplified in C. mollissima and C. seguinii and 80\% (14 from C. crenata and 30 from $C$. sativa) for $C$. henryi (Table 2). Among the successfully amplified loci, 32 (58.2\%), 33 (60\%), and $33(60 \%)$ loci were found to be polymorphic in C. mollissima, C. seguinii, and $C$. henryi, and the other 15 (27.3\%), 14 (25.5\%), and $11(20 \%)$ were monomorphic, respectively (Table 1). A high percentage of C. crenata markers revealed polymorphism in C. mollissima (13 of 14 loci, 92.9\%), C. seguinii, and C. henryi (14 of 14 loci, $100 \%)$, which is in good agreement with the results of Yamamoto et al. (2003), who claimed that all the SSR loci developed in the $C$. crenata could be applicable to C. mollissima and C. seguinii. However, they found two loci (KT006a and KT015a) that failed to amplify in C. henryi, which is more distant from the other species. Also, our results show a higher number of alleles at some loci and a larger size range than those reported by Yamamoto et al. (2003). For example, KT002a showed larger allele size range (243-252 bp) in C. seguinii than that in their study (243-249 bp). This difference may be the result of a larger sample size assayed in this study. In contrast, only 19 loci $(46.3 \%)$ developed from $C$. sativa showed polymorphism in the three Chinese species. This is in agreement with results that $C$. sativa and $C$. dentata are more closely related to each other than to the Asian species (Lang et al., 2006, 2007). The increase of evolutionary distance might result in a decline of cross-species amplification success rate. In addition, China and Japan are geographically close, thus interspecific introgression might have been taken place between Chinese Castanea species and C. crenata. This also could have led to a higher transferability between Japanese and Chinese chestnuts.

Among the polymorphic loci, a total of 132,153 , and 157 alleles were detected from each of the three random populations containing 30 individuals of $C$. mollissima, $C$. seguinii, and $C$. henryi, with the average value of 4.12 (from 2 to 7 ), 4.64 (from 2 to 8 ), and 4.76 (from 2 to 13 ) alleles per locus (Table 1). A high level of genetic diversity was observed in the three Chinese chestnut populations, with the mean observed heterozygosity $\left(H_{\mathrm{O}}\right)$ of 0.440 (from 0.065 to 1.000 ) in C. mollissima, 0.549 (from 0.100 to 0.950 ) in C. seguinii, and 0.508 (from 0.065 to 1.000 ) in $C$. henryi, and the average expected heterozygosity $\left(H_{\mathrm{E}}\right)$ was 0.506 (from 0.062 to 0.778 ) in $C$. mollissima, 0.615 (from 0.375 to 0.815 ) in C. seguinii, and 0.605 (from 0.063 to 0.882 ) in C. henryi, respectively (Table 1). A high level of heterozygosity is commonly observed in Castanea species (e.g., C. dentata: $H_{\mathrm{O}}=0.755, H_{\mathrm{E}}=0.818$, Kubisiak and Roberds, 2006; C. crenata: $H_{\mathrm{O}}=0.727, H_{\mathrm{E}}=$ 0.780 , Tanaka et al., 2005), which can be explained by the outbreeding nature of species in the genus.

The combined values (overall loci) for the first parent total exclusionary power $\left[\operatorname{Pr}\left(E x_{1}\right)\right]$ were estimated to be 0.9894 , 0.9989 , and 0.9905 for $C$. mollissima, $C$. seguinii, and $C$. 


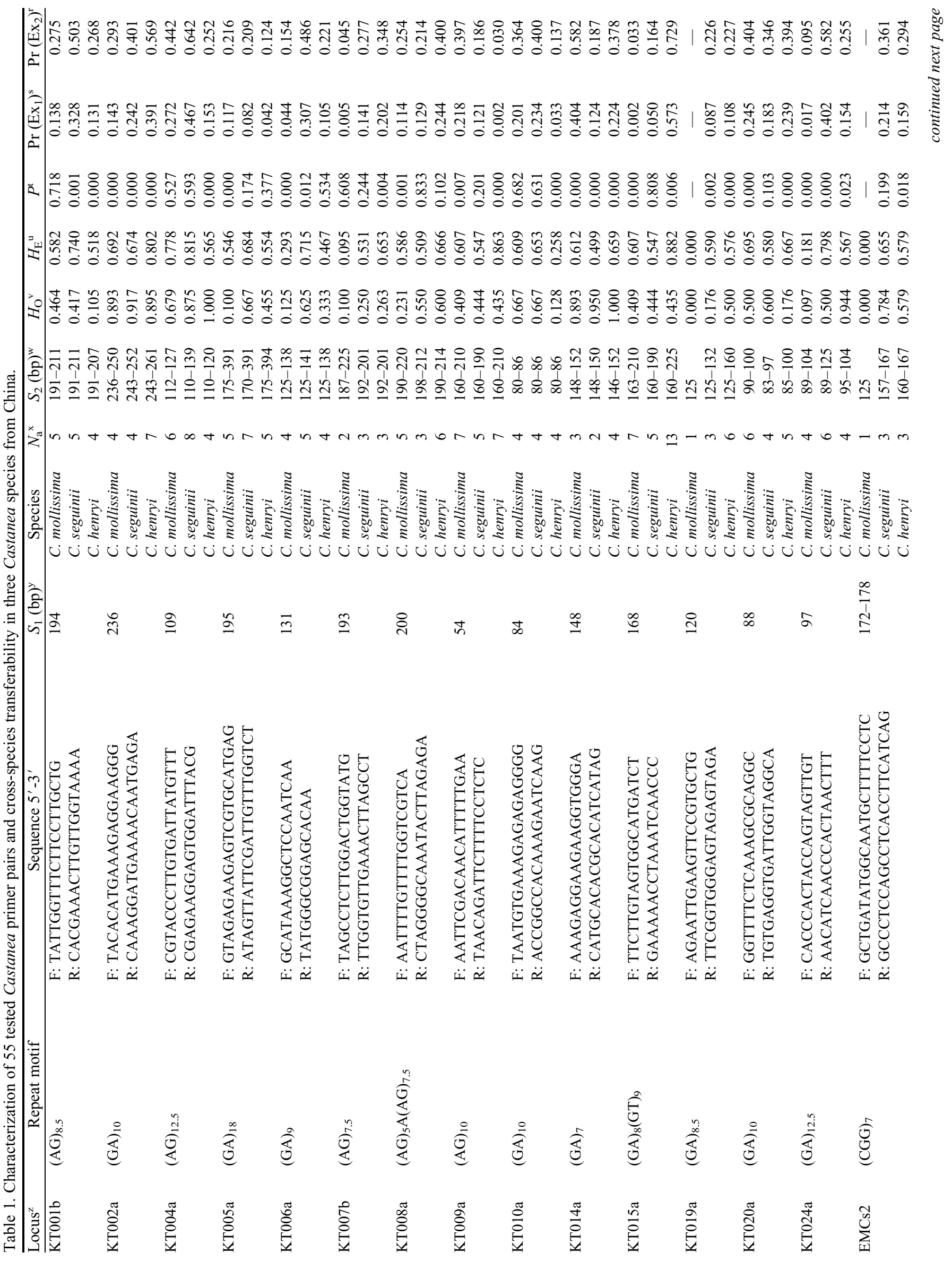




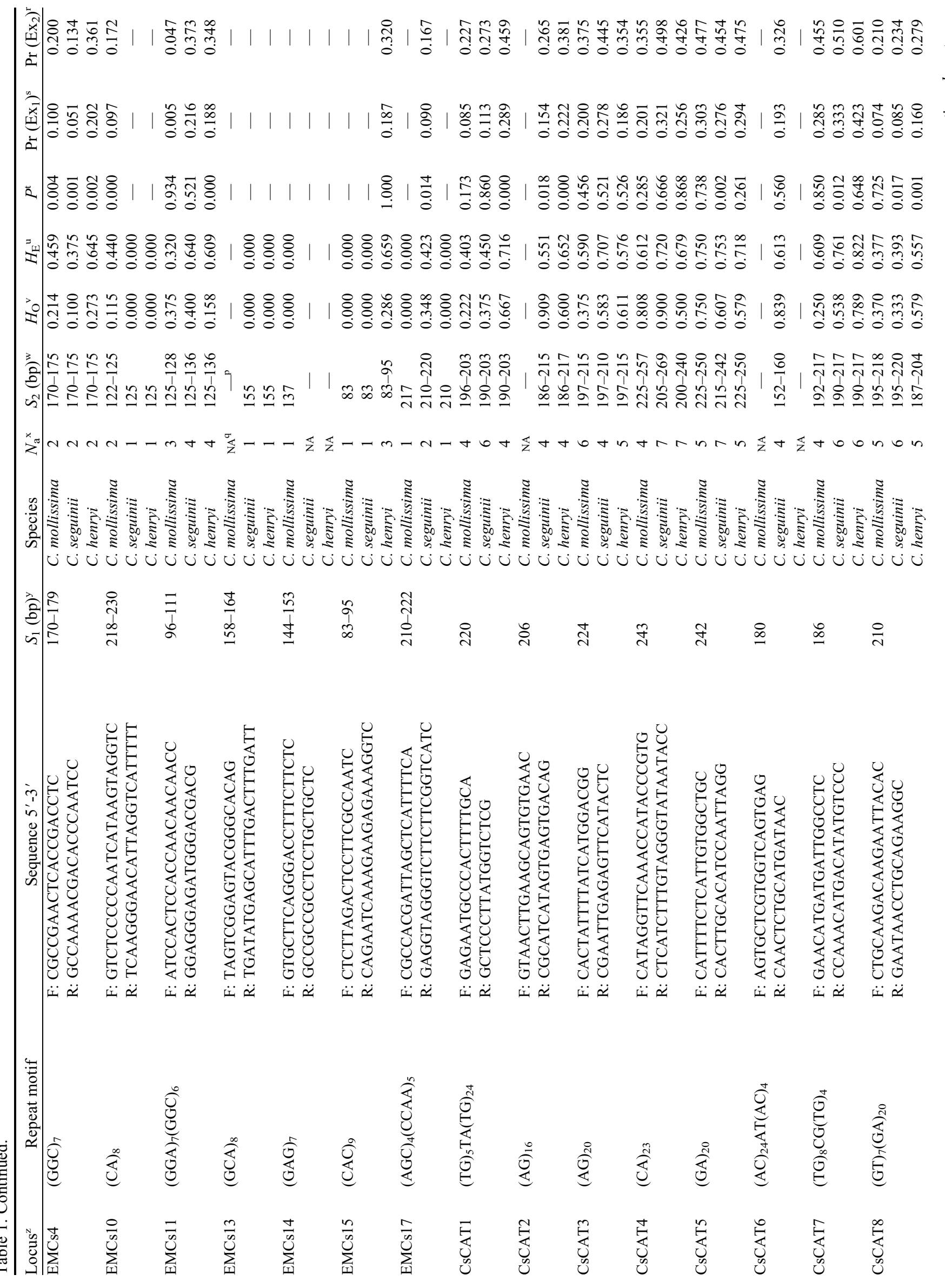




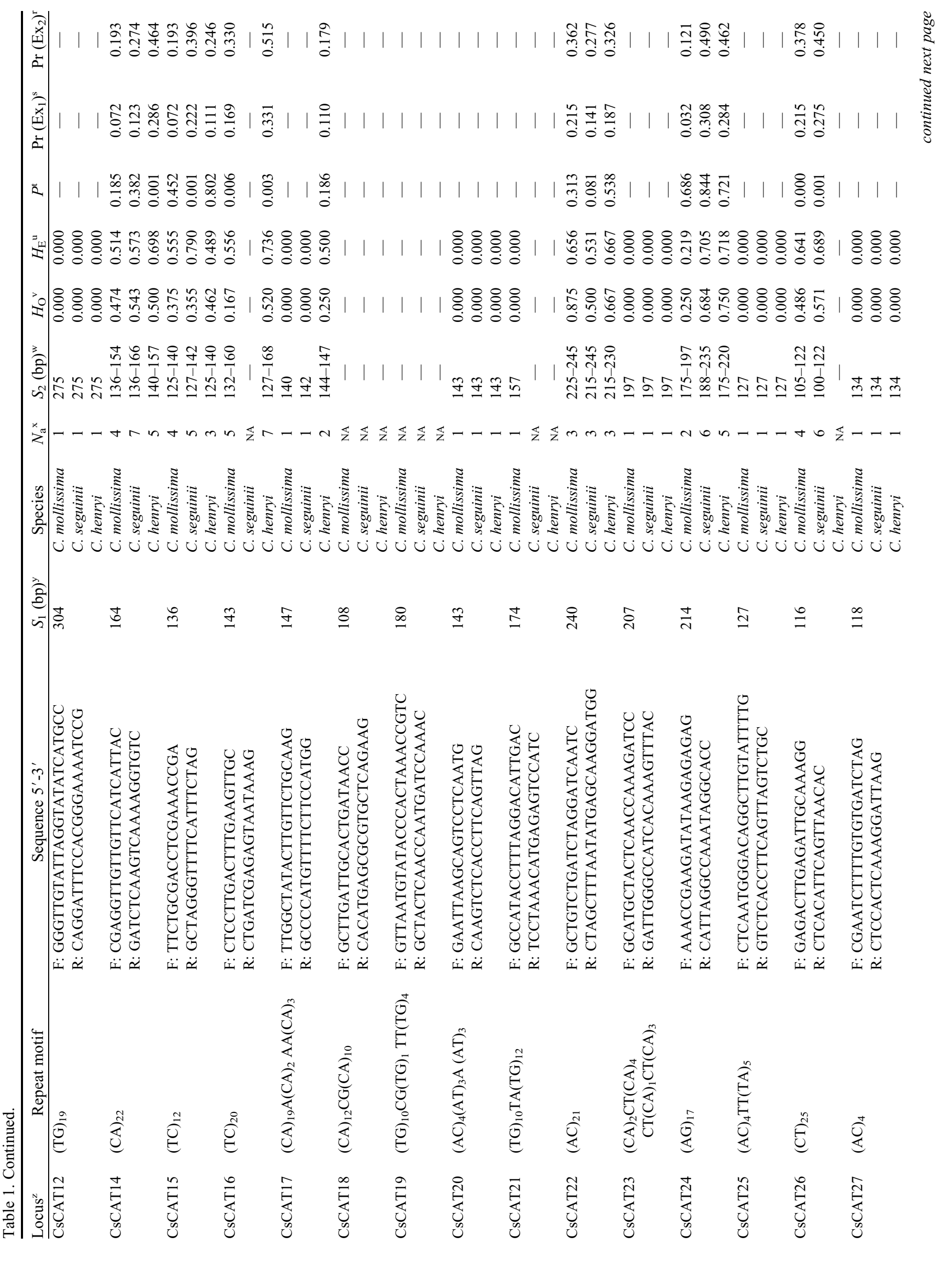




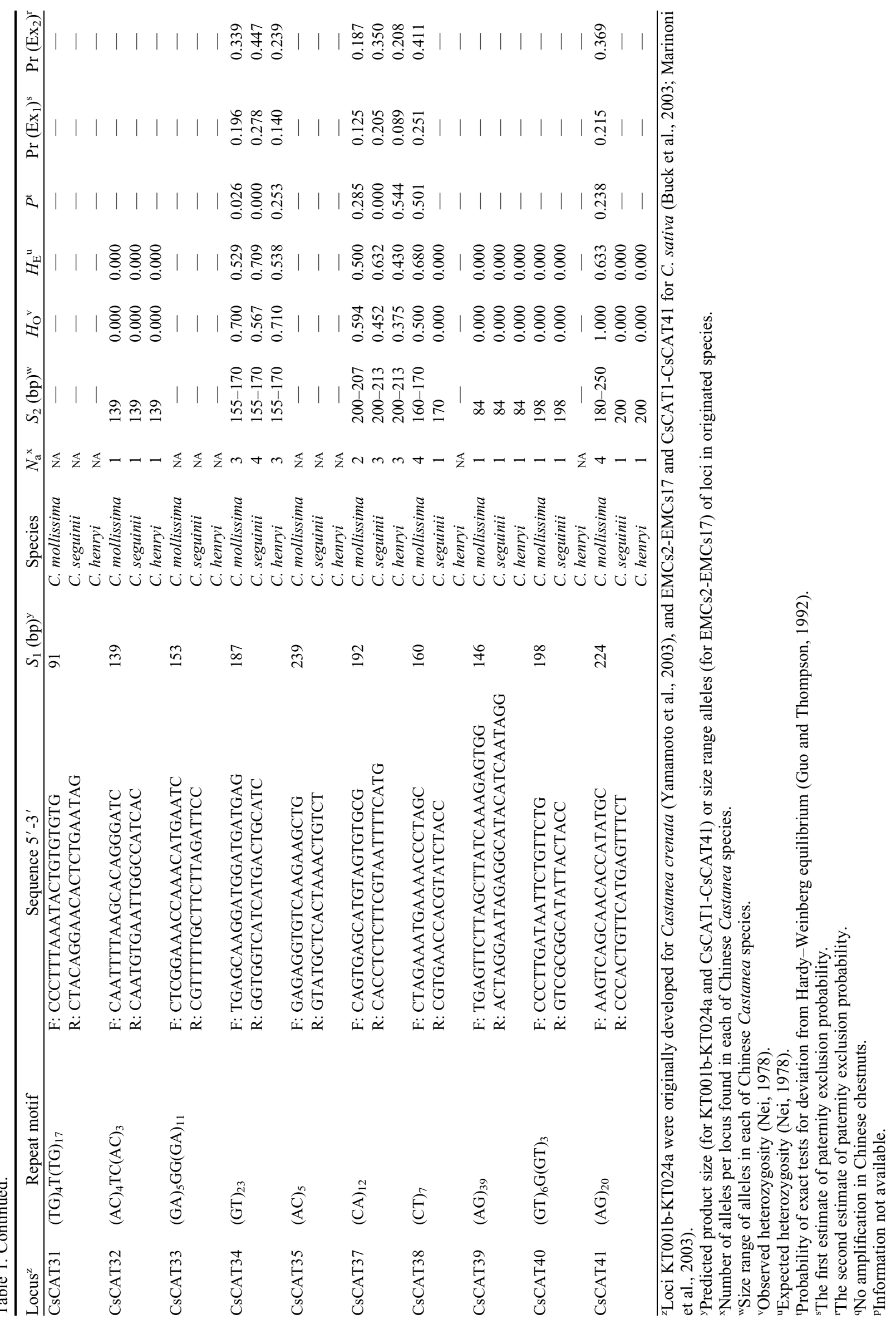



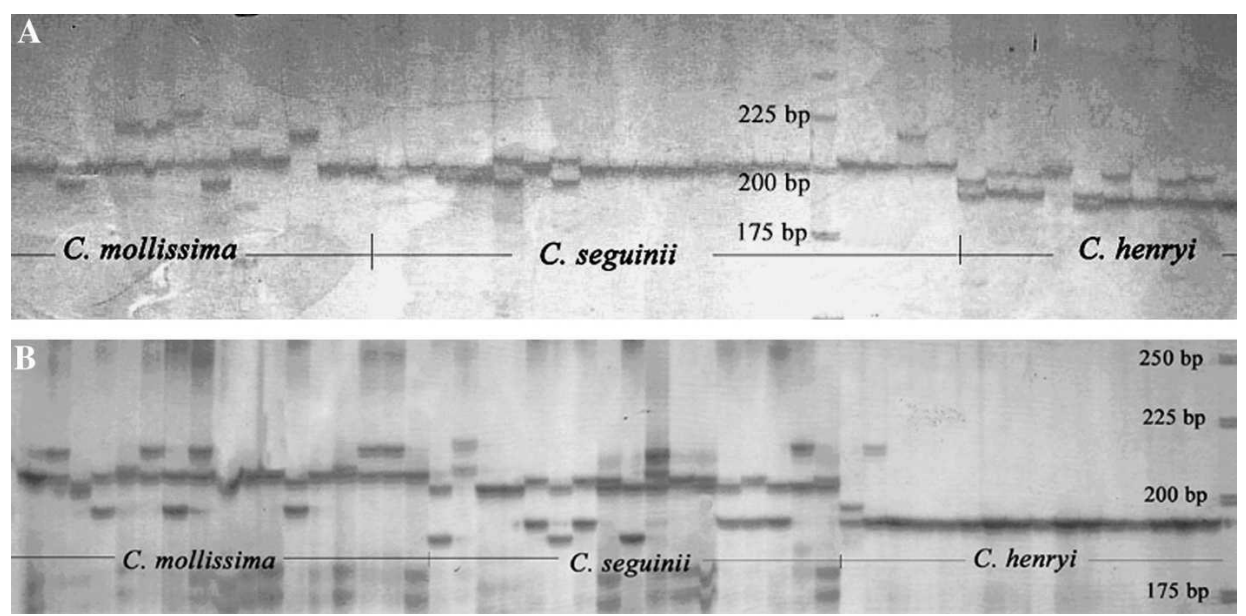

Fig. 1. Transferability of two microsatellite loci in three Chinese Castanea species: (A) CsCAT8 from C. sativa and (B) KT001b from C. crenata.

henryi, respectively, whereas if the genotype of one parent is known, the combined values for the total exclusionary power for the second parent $\left[\operatorname{Pr}\left(E x_{2}\right)\right]$ were 0.9999, 0.9999, and 0.9998 for three chestnuts, indicating that these microsatellite loci are suitable for paternity analysis. High polymorphism and the codominant nature of microsatellite alleles in most cases permits the exclusion of all potential pollen donors only with the use of small number of loci (Dow and Ashley, 1996; Kameyama et al., 2000; Streiff et al., 1999; Wang et al., 2008). Gene flow analysis using microsatellites polymorphism has been conducted on many wind-pollinated plants (e.g., Nakanishi et al., 2005; Streiff et al., 1999). The high resolution of this set of microsatellites tested in our study should provide a suitable tool for parentage analysis in breeding programs and pollen and/or seed-mediated gene flow studies for this monoecious and wind-pollinated genus.

Of the 55 loci analyzed, 14, 16, and 19 loci deviated from HWE in C. mollissima, C. seguinii, and C. henryi, respectively, after a Bonferroni correction for multiple tests $(P<0.05$, Table $1)$. This might be due to the limitation of sample size or the existence of null alleles. In addition, significant LD were discovered in four pairs of loci (KT001b/KT004a, KT008a/ $\mathrm{KT} 010 \mathrm{a}, \mathrm{KT} 005 \mathrm{a} / \mathrm{CsCAT} 26$, and CsCAT3/EMCs4) in $C$. mollissima, eight pairs of loci (KT002a/KT004a, KT008a/ KT019a，KT019a/KT024a，KT002a/CsCAT2，KT006a/ CsCAT2, KT009a/CsCAT3, KT008a/CsCAT8, KT019a/ CsCAT8, and CsCAT3/EMCs11) in C. seguinii and two pairs of loci (KT005a/KT007b and KT002a/CsCAT4) in C. henryi, respectively $(P<0.05$ after Bonferroni's correction). This is probably due to the small sample size and should be considered before analyses using these loci. However, a difference of microsatellite transferability between the three chestnuts was revealed. Several primer pairs were found to be specific in one or two species, such as EMCs14 and CsCAT21 were amplified only in C. mollissima, while CsCAT38 was amplified only in $C$. mollissima and C. seguinii. Also, some loci showed monomorphism in one species, but polymorphism in the other species. For example, KT019a and EMCs2 identified monomorphic loci in C. mollissima, while polymorphic loci were found in C. seguinii and C. henryi (Table 1). Most alleles are shared, which may be due to the shared ancestral variation and/or the recent gene flow resulting from interspecific hybridization. The allele number of loci was found to vary among the species, but species-specific alleles were detected. KT007b showed the 225-bp allele only in C. mollissima, CsCAT12 identified the 300-bp allele only in C. seguinii, and CsCAT16 showed the 168-bp allele only in C. henryi. Although SSR allele specificity needs to be further verified among Chinese chestnut species, these alleles that were found in only one species may provide a potential tool for studying interspecific hybridization and for facilitating the analysis of hybridization among these three closely related species for markerassisted selection. Artificial interspecific crosses among chestnuts have been used to introgress disease and/or pest resistance traits in chestnut breeding programs (e.g., Clapper, 1954; Diller and Clapper, 1969). Molecular markers such as allozymes also have been applied in chestnut breeding (Huang et al., 1994). Therefore, these highly polymorphic SSR loci would be more favorable to breeding programs in genus Castanea.

It was suggested that the successful cross-species transferability of microsatellites in plants is largely restricted to congeners and tends to decrease proportionally to phylogenetic divergence between target species and the "source species" of microsatellites (Barbará et al., 2007; Peakall et al., 1998; Roa et al., 2000; Varshney et al., 2005;). The Chinese chestnut species are considered the most ancestral species in genus Castanea (Lang and Huang 1999; Lang et al., 2006), and the high transferability $(>80.0 \%)$ of microsatellite loci revealed a close relationship among these five species used in the present study. Castanea henryi belongs to the section Hypocastanon Dode of the genus, but the other two Chinese chestnut species (C. mollissima and C. seguinii) and the two "source species" of microsatellites $(C$. crenata and $C$. sativa $)$ are included in section Eucastanon Dode. Castanea mollissima has a closer

Table 2. Transferable microsatellite loci among Castanea species.

\begin{tabular}{|c|c|c|c|c|c|c|c|}
\hline \multirow[b]{3}{*}{ Source species } & \multirow{3}{*}{$\begin{array}{c}\text { Loci } \\
\text { tested (no.) }\end{array}$} & \multicolumn{6}{|c|}{ Target species } \\
\hline & & \multicolumn{2}{|c|}{ C. mollissima } & \multicolumn{2}{|c|}{ C. seguinii } & \multicolumn{2}{|c|}{ C. henryi } \\
\hline & & Amplification & Polymorphism & Amplification & Polymorphism & Amplification & Polymorphism \\
\hline Castanea crenata & 14 & $14(100 \%)^{z}$ & $13(92.9 \%)$ & $14(100 \%)$ & $14(100 \%)$ & $14(100 \%)$ & $14(100 \%)$ \\
\hline Total & 55 & $47(85.5 \%)$ & $32(58.2 \%)$ & $47(85.5 \%)$ & $33(60.0 \%)$ & $44(80.0 \%)$ & $33(60.0 \%)$ \\
\hline
\end{tabular}

${ }^{\mathrm{z}}$ Percentages of transferable loci. 
relationship to $C$. seguinii than $C$. henryi (Lang and Huang, 1999), which is well supported by molecular phylogeny analysis (Lang et al., 2007). The percentage of transferability among species belonging to the same section was high $(C$. mollissima and $C$. seguinii, 85.5\%), whereas that belonging to different sections was slightly lower ( $C$. henryi, $80.0 \%)$. Therefore, the transferability of microsatellite primers in Castanea was in good agreement with currently accepted phylogeny of the genus.

This article demonstrates cross-species amplification of a set of microsatellite primers in the genus Castanea. The fact that over half of microsatellite primers designed for $C$. sativa and $C$. crenata can be applied in the three Chinese chestnut species suggests that these microsatellites are relatively conserved in the genus. Likewise, these markers can be widely applicable to other members of Castanea. Yamamoto et al. (2003) have proved the successful transferability of the microsatellite primers of $C$. crenata to other Castanea species (including the three Chinese chestnut species, C. sativa, and C. dentata). Kubisiak and Roberds (2006) studied the population structure of $C$. dentata using six microsatellite markers from $C$. sativa. Furthermore, Barreneche et al. (2004) tested the transferability of microsatellites of Castanea to Quercus L., a genus of the Fagaceae. Therefore, these microsatellite loci should provide a powerful tool for chestnut breeding programs and for conservation genetic studies of Chinese endemic Castanea species and other species of this genus.

\section{Literature Cited}

Barbará, T., C. Palma-Silva, G.M. Paggi, F. Bered, M.F. Fay, and C. Lexer. 2007. Cross-species transfer of nuclear microsatellite markers: Potential and limitations. Mol. Ecol. 16:3759-3767.

Barreneche, T., C. Bodenes, C. Lexer, J.F. Trontin, S. Fuchs, R. Streiff, C. Plomoin, G. Roussel, H. Steinkellner, K. Burg, J.M. Favre, J. Glössl, and A. Kremer. 1998. A genetic linkage map of Quercus robur L. (pedunculate oak) with RAPD, SCAR, microsatellite, minisatellite, isozyme and rDNA markers. Theor. Appl. Genet. 97:1090-1103.

Barreneche, T., M. Casasoli, K. Russell, A. Akkak, H. Meddour, C. Plomion, F. Villani, and A. Kremer. 2004. Comparative mapping between Quercus and Castanea using simple-sequence repeats (SSRs). Theor. Appl. Genet. 108:558-566.

Buck, E.J., M. Hadonou, C.J. James, D. Blakesley, and K. Russell. 2003. Isolation and characterization of polymorphic microsatellites in european chestnut (Castanea sativa Mill.). Mol. Ecol. Notes 3:239-241.

Bushar, L.M., M. Maliga, and H.K. Reinert. 2001. Cross-species amplification of Crotalus horridus microsatellites and their application in phylogenetic analysis. J. Herpetol. 35:532-537.

Butcher, P.A., S. Decroocq, Y. Gray, and G.F. Moran. 2000. Development, inheritance and cross-species amplification of microsatellite markers from Acacia mangium. Theor. Appl. Genet. 101:1282-1290.

Clapper, R.B. 1954. Chestnut breeding, techniques and results. J. Hered. 45:107-114.

Diller, J.D. and R.B. Clapper. 1969. Asiatic and hybrid chestnut trees in the eastern United States. J. For. 67:328-331.

Dow, B.D. and M.V. Ashley. 1996. Microsatellite analysis of seed dispersal and parentage of saplings in bur oak, Quercus macrocarpa. Mol. Ecol. 5:615-627.

Doyle, J.J. and J.L. Doyle. 1987. A rapid DNA isolation procedure for small quantities of fresh leaf material. Phytochem. Bul. 19:11-15.

Guo, S.W. and E.A. Thompson. 1992. Performing the exact test of Hardy-Weinberg proportion for multiple alleles. Biometrics 48:361372.
Huang, H.W., F. Dane, and J.D. Norton. 1994. Genetic analysis of 11 polymorphic isozyme loci in chestnut species and characterization of chestnut cultivars by multi-locus allozyme genotypes. J. Amer. Soc. Hort. Sci. 119:840-849.

Jaynes, R.A. 1979. Nut tree culture in North America. Northern Nut Growers Assn. Press, Hamden, CT.

Johnson, G.P. 1988. Revision of Castanea Sect. Balanocastanon (Fagaceae). J. Arnold Arboretum 69:25-49.

Kameyama, Y., Y. Isagi, K. Naito, and N. Nakagoshi. 2000. Microsatellite analysis of pollen flow in Rhododendron metternichii var. hondoense. Ecol. Res. 15:263-269.

Kubisiak, T.L. and J.H. Roberds. 2006. Genetic structure of american chestnut populations based on neutral DNA markers, p. 109-122. In: K.C. Steiner and J.E. Carlson (eds.). Restoration of american chestnut to forest lands: Proceedings of a conference and workshop. North Carolina Arboretum. Natural Resources Rpt. NPS/ NCR/CUE/NRR-2006/001, National Park Service, Washington, DC. Kuleung, C., P.S. Baenziger, and I. Dweikat. 2004. Transferability of SSR markers among wheat, rye, and triticale. Theor. Appl. Genet. 108:1147-1150.

Lang, P. 2004. Phylogeny and biogeography of Castanea (Fagaceae) based on chloroplast sequence data. Auburn University, Auburn, AL, PhD Diss.

Lang, P. and H.W. Huang. 1999. Genetic diversity and geographic variation in natural populations of the endemic Castanea species in China. Acta Bot. Sin. 41:651-657.

Lang, P., F. Dane, and T.L. Kubisiak. 2006. Phylogeny of Castanea (Fagaceae) based on chloroplast trnT-L-F sequence data. Tree Genet. Genomes 2:132-139.

Lang, P., F. Dane, T.L. Kubisiak, and H.W. Huang. 2007. Molecular evidence for an Asian origin and a unique westward migration of species in the genus Castanea via Europe to North America. Mol. Phylogenetic Evol. 43:49-59.

Marinoni, D., A. Akkak, G. Bounous, K.J. Edwards, and R. Botta. 2003. Development and characterization of microsatellite markers in Castanea sativa (Mill.). Mol. Breed. 11:127-136.

Marshall, T.C., J. Slate, L.E.B. Kruuk, and J.M. Pemberton. 1998. Statistical confidence for likelihood-based paternity inference in natural populations. Mol. Ecol. 7:639-655.

Nakanishi, A., N. Tomaru, H. Yoshimaru, T. Manabe, and S. Yamamoto. 2005. Interannual genetic heterogeneity of pollen pools accepted by Quercus salicina individuals. Mol. Ecol. 14:4469-4478.

Nei, M. 1978. Estimation of average heterozygosity and genetic distance from a small number of individuals. Genetics 89:583-590.

Peakall, R. and P.E. Smouse. 2006. GENALEX 6: Genetic analysis in Excel. Population genetic software for teaching and research. Mol. Ecol. Notes 6:288-295.

Peakall, R., S. Gilmore, W. Keys, M. Morgante, and A. Rafalski. 1998. Cross-species amplification of soybean (Glycine max) simple sequence repeats (SSRs) within the genus and other legume genera: Implications for the transferability of SSRs in plants. Mol. Biol. Evol. 15:1275-1287.

Raymond, M. and F. Rousset. 1995. GENEPOP (Version 1.2): Population genetics software for exact tests and ecumenicism. J. Hered. 86:248-249.

Roa, A.C., C.A. Paul, C.D. Myriam, M.M. Maya, M.W. Bonierbale, C. Iglesias, and J. Tohme. 2000. Cross-species amplification of cassava (Manihot esculenta) (Euphorbiaceae) microsatellites: Allelic polymorphism and degree of relationship. Amer. J. Bot. 87:1647-1655.

Rutter, P.A., G. Miller, and J.A. Payne. 1990. Chestnut, p. 761-788. In: J.N. Moore and J.R. Ballington Jr. (eds.). Genetic resources of temperate fruit and nut crops. Intl. Soc. Hort. Sci., Wageningen, The Netherlands.

Sanguinetti, C.J., E.D. Neto, and A.J.G. Simpson. 1994. Rapid silver staining and recovery of PCR products separated on polyacrylamide gels. Biotechniques 17:914-921.

Schnell, R.J., C.T. Olano, W.E. Quintanilla, and A.W. Meerow. 2005. Isolation and characterization of 15 microsatellite loci from mango 
(Mangifera indica L.) and cross-species amplification in closely related taxa. Mol. Ecol. Notes 5:626-627.

Steinkellner, H., C. Lexer, E. Turetschek, and J. Glössl. 1997. Conservation of $(\mathrm{GA})_{\mathrm{n}}$ microsatellite loci between Quercus species. Mol. Ecol. 6:1189-1194.

Streiff, R., A. Ducousso, C. Lexer, H. Steinkellner, J. Glössl, and A. Kremer. 1999. Pollen dispersal inferred from paternity analysis in a mixed oak stand of Quercus robur L. and Q. petraea (Matt.). Liebl. Mol. Ecol. 8:831-841.

Tanaka, T., T. Yamamoto, and M. Suzuki. 2005. Genetic diversity of Castanea crenata in northern Japan assessed by SSR markers. Breed. Sci. 55:271-277.
Varshney, R.K., A. Graner, and M.E. Sorrells. 2005. Genetic microsatellite markers in plants: Their features and applications. Trends Biotechnol. 23:48-55.

Wang, J., Q. Ye, M. Kang, and H. Huang. 2008. Novel polymorphic microsatellite loci and patterns of pollen-mediated gene flow in an ex situ population of Eurycorymbus cavaleriei (Sapindaceae) as revealed by categorical paternity analysis. Conserv. Genet. 9:559567.

Yamamoto, T., T. Tanaka, K. Kotobuki, N. Matsuta, M. Suzuki, and T. Hayashi. 2003. Characterization of simple sequence repeats in japanese chestnut. J. Hort. Sci. Biotechnol. 78:197203. 